series of selected specimens has been arranged and exhibited at various soiríes. This exhibition series is being enlarged.

Owing to the generosity of Mr. J. P. Thomasson, who has made a second donation of $£ 250$ for this purpose, it has been possible for the council to retain the services of Mr. Holt for fishing inquiries in the North Sea for a second year.

Mr. Garstang has been appointed for a second year to superintend the collection, preservation, and supply of material. The character of the specimens supplied by the laboratory has improved very greatly under his care.

Mr. Cunningham has continued his observations on the rate of growth and probable ages of young fish, a paper on which was published in the November number of the Association's journal. He has also continued his experiments on the colouration of the under-side of flat-fishes. Since Christmas he has been occupied in an inquiry into the question of the destruction of immature fish, the first results of which appear in the May number of the journal.

Mr. Cunningham has also succeeded in artificially fertilising the eggs of the flounders which he has reared in the laboratory tanks during the last three years from a length of half an inch the eggs developed, and the larvæ were artificially fed for ten days after the absorption of the yolk-sac. This result is of great importance and interest.

Mr. Holt has been at work now for eighteen months upon an investigation of the fisheries of the North Sea, and his papers in the journals for November and May supply a large amount of important information. The Council contribute to the expenses of the Cleethorpes Aquarium of the Marine Fisheries Society (Grimsby) in return for Mr. Holt's use of their laboratory and tanks.

Mr. Garstang has captured a large number of rare forms during the past year, and he has added five new species to the list of the British fauna. As a result of his work during the past year, an intimate knowledge of the localities of the fauna has been acquired, so that specimens can be obtained without delay.

The receipts for the past year include the annual grants from H.M. Treasury ( $£$ IOOo) and the Worshipful Company of Fishmongers $(£ 400)$; annual subscriptions have produced $£ \mathbf{r} 60$ composition fees $£ \mathbf{r} 6$, the rent of tables at the laboratories, $£ 34$, the sale of specimens $£ 205$, and the admission to the tank-room $£ 70$, the total amounting, with lesser sums, to $£ 2199$.

The Vice-Presidents, Officers, and Council proposed by the Council for 1893-94 are :- President : Prof. E. Ray Lankester, F.R.S. ; Vice-Presidents : The Duke of Argyll, K.G., K.T., F.R.S., the Duke of Abercorn, K.G., C. B., the Earl of St. Germans, the Earl of Morley, the Earl of Ducie, F.R.S., Lord Walsingham, F.R.S., Lord Revelstoke, the Right Hon. A. J. Balfour, M.P., F.R.S., the Right Hon. Joseph Chamberlain, M.P., Prof. G. J. Allman, F.R.S., Sir Edward Birkbeck, Bart., M.P., Sir Wm. Flower, K.C.B., F.R.S., the Right Hon. Sir John Lubbock, Bart., M.P., F.R.S., Prof. Alfred Newton, F.R.S., Sir Henry Thompson, Rev. Canon Norman, F.R.S., Captain Wharton, R.N., F.R.S. ; Council-elected Members: F. E. Beddard, F.R.S., Prof. F. Jeffrey Bell, Prof. W. A. Herdman, F.R.S., Sir John Evans K.C.B., F.R.S. A. C. L. G. Günther, F.R.S., Prof. A. C. Haddon, Dr. Sydney J. Hickson, Prof. W. C. McIntosh, F.R.S., Right Hon. E. Majoribanks, M.P., E. B. Poulton, F.R.S., P. L. Sclater, F. R.S., Adam Sedgwick, F. R.S., Prof. Charles Stewart, Prof. W. F. R. Weldon, F.R.S., Hon. Treasurer : E.L. Beckwith Hon. Secretary: G. Herbert Fowler.

\section{THE CONDITIONS DETERMINATIVE OF CHEMICAL CHANGE.}

NOTWITHSTANDING the large amount of evidence now placed on record that substances commonly supposed to be capable of directly interacting do so only in the presence of at least one other substance, chemists do not appear to have arrived at any clear and consistent understanding of the conditions determinative of chemical change : as each fresh case is recorded, we continue to express surprise, overlooking the fact that Faraday, in his early "Experimental Researches in Electricity," clearly foresaw what the conditions were, and that but a slight exten-

1 Reprinted from the Pruccedings of the Chenical Society, No. 125 . No. I 236 , voL. 48 ] sion of his generalisations is needed to frame a comprehensive theory. The subject is of such importance that it appears to me desirable to discuss the bearing of recent observations, especially as they to some extent necessitate the modification of views that I have expressed elsewhere, and in order to attract the attention of physicists, to whom we must now look for guidance in these matters.

Eight years ago, in the course of the discussion on Mr. H. B. Baker's communication on combustion in dried gases (Proc. Chem. Soc., 1885,40 ), I defined chemical action as reversed electrolysis: in other words, in order that chemical action may take place, it is essential that the system operated on comprise an electrolyte. I then pointed out that as neither hydrogen nor oxygen was an electrolyte, a mixture of only these two gases should not be explosive; and, moreover, as water was not an electrolyte, and it was scarcely probable that water and oxygen or hydrogen would form an electrolyte, it was difficult to understand how the presence of water pure and simple should be of influence in the case of a mixture of hydrogen and oxy. gen. This forecast has since been verified, the remarkable series of experiments carried out by V. Meyer in conjunction with Krause and Askenasy having clearly demonstrated that the formation of water from hydrogen and oxygen takes place at an irregular rate, and is, therefore, dependent on the presence of a something other than water-I imagine an acid impurity. But this is a consideration which has not yet received the proper attention, and it is, therefore, desirable to emphasise its importance by reference to other cases. Mr. Baker's recent preliminary note on the influence of moisture in promoting chemical action (ante, p. 229) affords several interesting examples:- Thus, he states that neither does hydrogen chloride combine with ammonia, nor is nitric oxide oxidised by oxygen if moisture be excluded. In the former case, the addition of water should suffice to determine the combination, as water and hydrogen chloride together form a " composite electrolyte" (cf. Roy. Soc. Proc., 1886, No. 243 , p. 268); as neither nitric oxide nor oxygen, however, forms a composite electrolyte with water, in this case water alone should not determine the occurrence of change; but if, by the introduction of a trace of "impurity" in addition to water the presence of a composite electrolyte were secured (however high its resistance, owing to the smallness of the amount of "im. purity"), action would set in, and when once commenced would proceed at an increasing rate, as nitric acid would be formed and the resistance of the electrolyte would consequently diminish. On this account it will be a task of exceeding diff. culty to experimentally demonstrate that nitric oxide and oxygen are inactive in presence of water alone; but there can be no doubt that such must eventually be admitted to be the case, provided always that it is permissible to extrapolate Kohlrausch's observatious, and to conclude from them that pure water is a dielectric. The gradual increase in the rate of change here contemplated corresponds to the period of induction observed by Bunsen and Roscoe in their observa ions on the interaction of chlorine and hydrogen; the statement recently made by Bodenstein and V. Meyer (Berichte, 1893, 1146) that a mixture of chlorine and hydrogen behaves irregularly on exposure to light is a valuable confirmation of Pringsheim's observations, and there is now no room for doubt that pure chlorine and hydro. gen would be incapable of interacting. That no such irregularity is observed on heating iodine with hydrogen is not surprising, as hydrogen iodide would be formed from the very outset, and the electrolyte present would exert a minimum resistance almost at once. There is, however, a significant difference in the behaviour of the two mixtures, as hydrogen chloride should behave as hydrogen iodide, so that the problem is but incompletely solved: it may be that the one mixture was more nearly pure than the other, or it may be that the formation of hydrogen chloride from hydrogen and chlorine, under the influence of light, is dependent on the presence of some particular subslance, together with water, and does not lake place under the influence of any substance capable of forming a composite electrolyte with water; probably, however, the difference observed is chiefly due to the fact that only one of the actions is reversible under the conditions prevailing in the experiments.

Lastly, attention may be directed to the formation of sulphuric oxide from sulphurous oxide and oxygen, which is readily effected in presence of a catalyst, such as finely divided platinum; it cannot be supfosed that the mere presence of platinum would condition the occurrence of change, and doubt less moisture is also necessary, the platinum or other catalys 
but serving to promote the oxidation of the sulphurous oxide at a temperature considerably below that at which sulphuric oxide decomposes when heated. The action of surfaces generally may well be of this character, and the converse influence they so frequently exercise is probably an effect of the same order.

I have elsewhere raised the question whether there may not be a difference between actions taking place under the influence of low and of high electromotive forces-whether water, per se, may not be an electrolyte towards high, although not towards low, forces, in the case of high temperature changes, or those brought about under the influence of the electric spark, for example. More attentive consideration of the subject has led me to think that this is not the case, and that we must treat high temperature changes such as occur and are involved in gaseous explosions in the same way as those occurring under ordinary conditions and at low temperatures. From this point of view, Mr. Baker's statement that ammonia and hydrogen chloride do not combine is of extreme importance; the formation of ammonium chloride from these two compounds apparently involves no interchange, but a mere combination of two substances each endowed with considerable "residual affinity," and there is no reason why a distinction should be drawn between such a case and that afforded by, say, atoms of hydrogen and oxygen, the difference being, it would seem, one of degree only; in fact, I am no longer inclined to believe that atoms are capable of directly uniting. In all cases at least one function of the (composite) electrolyte would appear to be that of providing the necessary "mechanism" whereby the degradation or discharge of the energy is effected. If this argument be sound, its logical extension involves the conclusion that pure gases should be dielectrics, i.e. that the passage of an electric discharge through a gas like that of an explosive wave through, say, a mixture of hydrogen and oxygen, can only take place if an electrolyte be present. Hitherto but little attention has been paid to the electric discharge in gases which have been highly purified. The peculiar behaviour of Tesla tubes referred to by Mr. Crookes in the discussion on Mr. Shenstone's paper on the formation of ozone is, perhaps, explicable from this point of view -it may be that the atmosphere within the tube does not become conducting until sufficient moisture and "impurity" have been projected from its sides. It is conceivable that a similar explanation may hold good in the case of Prof. Schuster's observation, that it is possible to urge a current of low electromotive force across a gas subjected to a high electromotive force in itself insufficient to cause a discharge in the gas; the atomic dissociation hypothesis put forward in explanation of the phenomenon does not appear to me to be sufficient.

Finally, the question arises, Can no line be drawn; are no two pure substances capable of combining or interacting:-For example, water and sulphuric anhydride? There is little to guide us here, but it seems not unlikely that water has special properties which enable it to act directly; moreover-perhaps because-in such cases composite electrolytes would result. Ammonium chloride, so long as it remains solid, is clearly a compound of a different order, and it may well be that compounds of this type are in no case directly obtainable from their constituents, because, under the conditions under which they are formed, they cannot behave as electrolytes.

Apparently, in all cases in which molecular aggregates are formed-as in the case of solutions-we are dealing with dissociable and dissociating systems, and it is not improbable that we may ultimately find an explanation of the mechanism of such changes in this fact.

At present there is no information forthcoming whether simple electrolytes, such as fused silver chloride, for example, will condition chemical change in the way that water does-whether for instance, silver chloride will condition the formation of hydrogen chloride from chlorine and hydrogen, so that a gas battery might be constructed of these three substances.

Henry E. Armstrong.

THE SUCCESSION OF TEETH IN MAMMALS.

PROF. H. F. OSBORN, in the American Naturalist for June, gives an account of recent researches upon the suc sion of the teeth in mammals. He says :-

"The recent studies of Kükenthal, Röse, and Taeker in the $\mathrm{d}$ iscovery of the complete double or milk dentition in the MarNO. I $2 ; 6$, VOL. 48 ] supials, and in the discussion of its relation to that of the rep tiles, also in the ontogenesis of the crowns of the teeth among the Cetaceans, Edentates, Primates, and Ungulates are of the greatest interest and importance. They involve a complete revolution in our ideas as to the interpretation of the dentition in the three orders first mentioned above."

After giving an account of the work done by the European observers, Prof. Osborn shows, by means of a table, the phylogenetic order as observed by Cope and Osborn, and the ontogenetic order as observed by Röse and Taeker. His researches indicate that the earliest furms of mammals were homodont, and had two or more series of successional teeth. Then within the mammalian stem the teeth were differentiated, and there arose a great heterodont group with teeth at least of three hinds -incisors, premolars, and molars, all successional. From the most anterior premolar arose the canine. Then came the division between the Marsupials and the Placentals, the former tending to suppress the development of the second series of teeth, the latter retaining the second series as far back as the first molar. There is an obvious advantage in the line of succession being drawn at the first molar, ${ }^{1}$ for upon the molars rested the necessity of complex development, and such development was best effected in permanent crowns.

1. All the so-called "milk molars" plus the so-called "true molars" constitute the first serits. Beneath one or more of the "true molars" in lower mammals are rudiments of a second series. The second series con-ists therefore of these submolar rudiments plus the successional or permanent premolars, incisors and canines.

2. In the stem Marsupials the entire first series persisted and became mainly permanent (non-deciduous); the second series became rudimentary and non-successional with the exception of the fourth upper and lower premolars, and possibly one or two other teeth which either replaced or were intercalated between members of the first series. One or more premolars were suppressed, and one more molar retained than typical in the Placen tals. Thus is explained the apparently atypical dental formula of Marsupials.

3. In the stem heterodont Placentals (excepting the Cetacea and Edentata) the entire first series persisted, and all the in. cisors, canines, and premolars remained decidnous. The successional second series persisted as far back as the first molar.

4. In the stem Cetacea the entire first series persisted, and the second series became rudimentary and non-successional. The tooth form changed from a heterodont to a homodont type.

5. In the stem Edentates, which also transformed from the heterodont to the homodont type, the first series became rudimentary, and the second series persisted in the succession even behind the region of the first molar.

Finally, there is evidence that a primitive succession in the region of the molar teeth, lost in the Marsupials and in the Placentals, was more or less fully retained in the Cetacea and Edentates.

\section{UNIVERSITY AND EDUCATIONAL INTELLIGENCE.}

THE Governors of the Glasgow and West of Scotland Technical College have appointed Mr. W. H. Watkinson, lecturerer on engineering, Central Higher Grade School, Sheffield, to the Chair of steam, steam engines, and other prime movers, recently instituted in the college. By several important changes, the engineering department has been recently reorganised, Prof. Jamieson devoting his attention entirely to electrical engineering, Prof. Rowden to mechanics (theoretical and applied), Prof. MacSay to machine drawing, and Prof. Watkinson to the subjects stated above. With this addition and rearrangement the college now possesses an engineering staff worthy of one of the greatest engineering centres in the kingdom. Many additions are wanted, however, to bring the laburatories and general equipment to a position of equality with those even in many provincial towns.

1 The law of molar evolution is that complication is most rapid in teet which are longest in use. Thus the first molar is the most progressive thich of the true molar series, and the last premolar is the most progressive of of the premolar series. The ar permanent is explained by the fact that the milk premolars are formed to assume the molar function 